\title{
Research Activities for Nuclear Power Plant Aging Promoted by PLEC, JAPEIC, Japan*
}

\author{
Noriyoshi MAEDA** and Kenichi TAJIMA ${ }^{* * *}$
}

\begin{abstract}
In order to perform research activity for aging countermeasure of nuclear power plant effectively, Plant Life Engineering Center (PLEC) was established in Japan Power Engineering and Inspection Corporation (JAPEIC) in April 2000 sponsored by Ministry of International Trade and Industry (MITI, presently METI). Outlined activities of PLEC are as follows. Results of technical survey for research and development for aging phenomena have been summarized in a table (Research Map) categorizing them into "inspection and monitoring", "evaluation method for aging" and "preventive maintenances and refurbishment". Necessary research themes have been extracted from the Research Map consulting to experts of the specified research area and they are summarized into Medium and Long-term Research Perspective (Research Perspective), which contains prioritized research themes and outlined specification of each theme. Several new research themes proposed by various organizations and selected by PLEC as effective for the regulation activities are identified and proposed to be funded by METI every year. This paper also provides outlines and obtained results of aging related research projects currently conducted by JAPEIC sponsored by METI.
\end{abstract}

Key Words: Stress Corrosion Cracking, Low Cycle Fatigue, Nondestructive Inspection, Aging Countermeasure, Research Map, Research Perspective, Verification Test

\section{Introduction}

By the end of January 2003, 52 commercial nuclear power plants have been operating in Japan and they generate about $35 \%$ of the gross capacity of $45.7 \mathrm{GWe} .4$ plants constructed in the early 1970s have been operated for more than 30 years and 23 plants, including the above 4 plants, have been in operation for over 20 years. Thus, aging management of nuclear power plant has become a matter of increasing concern in Japan.

The regulatory bodies of Japan have endeavored to enhance the reliability and safety of aged nuclear power

* Received 27th October, 2003 (No. 03-4147)

** Nuclear Power Plant Life Engineering Center (PLEC), Japan Power Engineering and Inspection Corporation (JAPEIC), Shin-Toranomon BLDG., 1-5-11 Akasaka, Minato-ku, Tokyo, Japan.

E-mail: maeda-noriyoshi@ japeic.or.jp

*** Nuclear Power Plant Life Engineering Center (PLEC), Japan Power Engineering and Inspection Corporation (JAPEIC), Shin-Toranomon BLDG., 1-5-11 Akasaka, Minato-ku, Tokyo, Japan.

E-mail: tajima-kennichi@japeic.or.jp plants $^{(1)}$.

The electric utility companies conduct technical evaluations in their periodical safety reviews concerning the aging phenomena of all safety related components and structures. From the viewpoint of aging management, the companies identified additional maintenance measures to reinforce their current maintenance procedures and summarized them as their long-term maintenance programs including the current and additional maintenance activities. Figure 1 shows aging phenomena in major components and structures for evaluation of PWR nuclear power plants. For the implementation and promotion of aging-related technology research, PLEC was established in April 2000 in JAPEIC sponsored by Ministry of International Trade and Industry (MITI), presently called as Ministry of Economy, Trade and Industry (METI).

Technology Advisory Committee composed of members from academics, electric utilities, manufacturers and prefecture and municipal governments relevant to nuclear power plant sites recommend the PLEC activity to concentrate national wide potentials and to secure transparency, openness and neutrality. 


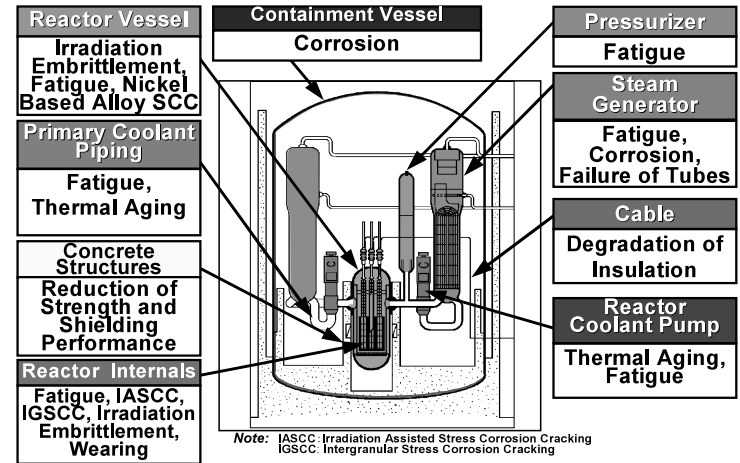

Fig. 1 Aging phenomena in major components and structures (PWR)

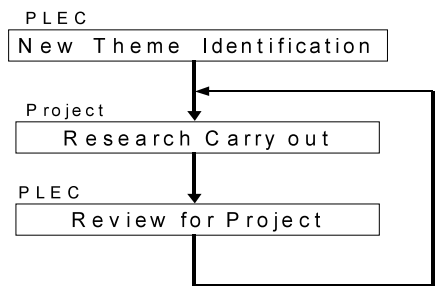

(a) General activities

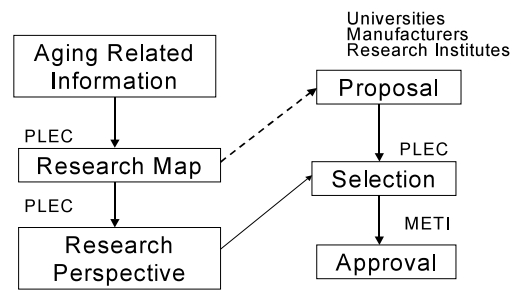

(b) Detailed activities for new theme identification

Fig. 2 Research activities promoted by PLEC

\section{PLEC Activities}

Assigned mission and roles of PLEC are as follows:

( a ) Coordinate planning of technology research on aging in cooperation with industry, government and academia

(b) Integrate technology knowledge of aging for management and assessment

(c ) Promote practical application of obtained technical results by national projects

(d ) Promote holding of technology information in common

Schematic presentation of research activities is depicted in Fig. 2(a). Detailed activities in New Theme Identification are shown in Fig. 2 (b).

\subsection{Preparation of research map}

Technical survey for research and development related to aging countermeasures are currently conducted and summarized in a type of matrix table that locates many existing researches on aging phenomena including 'neutron irradiation embrittlement', 'stress corrosion cracking', 'fatigue', 'thermal aging' and 'corrosion' categoriz-

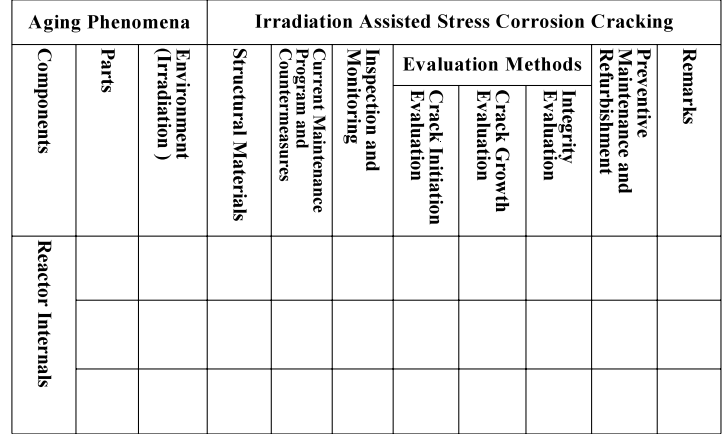

Fig. 3 Example of the research map for aging

ing them into three fields of 'inspection and monitoring', 'evaluation method for aging', and 'preventive maintenances and refurbishment'. Figure 3 shows a format example of the research map.

From these tables, necessary research items for safety regulation and facility maintenance management are extracted by experts of the specified research area.

\subsection{Development of medium and long-term re-} search perspective (Research Perspective)

In order to carry out researches effectively, efficiently and in a timely manner under the restriction of resources and period, Research Perspective has been established. It contains research themes prioritized based on their necessity and effectiveness as shown in Table 1. It also contains outlined research specification of each theme. One example of them for IGSCC in austenitic stainless steel is shown in Table 2.

\subsection{New themes identification}

Every October PLEC receives new research proposal from universities, manufacturers and research institutes such as JAERI (Japan Atomic Energy Research Institute) and CRIEPI (Central Research Institute of Electric Power Industry). Their order of priority is decided by the subcommittee from the viewpoints of consistency with $\mathrm{Re}$ search Perspective, urgency of the research, importance of the relevant component and effectiveness of the research to safety regulation. Selected themes are proposed as candidates for national projects.

There are two types of national project in the framework of aging related research of METI. One is called as Verification Test whose purpose is to establish essential database for a specified aging phenomenon and countermeasure technologies. A Verification Test is in many cases scheduled to be completed in several years. The other is called as Study of Safety-related Advanced Technology (SAT Study) whose purpose is to obtain basic data of aging phenomena, to recognize its general tendency or to understand its mechanism. A SAT study is to be completed in a year. 
Table 1 Themes in Research Perspective Note

${ }^{*}$ P: Priority, H: High, M: Middle

${ }^{* *}$ ASS: Austenitic stainless steel

\begin{tabular}{|c|c|}
\hline Research Items & $\mathrm{P}^{*}$ \\
\hline \multicolumn{2}{|l|}{ IRRADIATION EMBRITTLEMENT } \\
\hline Monitoring specimen reconstitution & $\mathrm{H}$ \\
\hline Integrity evaluation of USE $<68 \mathrm{~J}$ materials & $\mathrm{H}$ \\
\hline Effect evaluation of accelerated irradiation & $\mathrm{M}$ \\
\hline Embrittlement estimation by mechanism & $\mathrm{M}$ \\
\hline \multicolumn{2}{|l|}{ SCC IN Ni-BASED ALLOY } \\
\hline SCC detection/sizing by UT & $\mathrm{H}$ \\
\hline SCC detection/sizing by ECT & $\mathrm{M}$ \\
\hline SCC growth data & $\mathrm{H}$ \\
\hline SCC growth by constant load/displacement & $\mathrm{H}$ \\
\hline Effect of radiolytic products on SCC & $\mathrm{M}$ \\
\hline Mechanism of generation/growth of SCC & $\mathrm{M}$ \\
\hline Surface improvement for SCC & $\mathrm{M}$ \\
\hline \multicolumn{2}{|l|}{ FATIGUE } \\
\hline Crack detection/sizing by UT for Ni alloy & $\mathrm{M}$ \\
\hline Crack detection/sizing by ECT for Ni alloy & $\mathrm{H}$ \\
\hline Precision of crack detection/sizing by NDT & $\mathrm{M}$ \\
\hline Fatigue life data in reactor coolant & $\mathrm{M}$ \\
\hline Fatigue crack growth data in reactor coolant & $\mathrm{M}$ \\
\hline \multicolumn{2}{|l|}{ IASCC } \\
\hline SCC generation/growth data & $\mathrm{H}$ \\
\hline SCC growth by constant load/displacement & $\mathrm{H}$ \\
\hline Load variation effect on generation of SCC & $\mathrm{M}$ \\
\hline Effect evaluation of accelerated irradiation & $\mathrm{M}$ \\
\hline SCC data under irradiation & $\mathrm{M}$ \\
\hline Effect of radiolytic products on SCC & $\mathrm{M}$ \\
\hline He accumulation effect on material & $\mathrm{M}$ \\
\hline Irradiation effects on creep and stress relaxation & $\mathrm{M}$ \\
\hline Simulation of degradation by irradiation & $\mathrm{M}$ \\
\hline Weld repair for irradiated materials & $\mathrm{M}$ \\
\hline Surface improvement for SCC & $\mathrm{M}$ \\
\hline Repair for highly irradiated materials & $\mathrm{M}$ \\
\hline \multicolumn{2}{|l|}{ IGSCC } \\
\hline NDT for small crack in low carbon ASS ${ }^{* *}$ & $\mathrm{M}$ \\
\hline SCC data in reactor coolant & $\mathrm{M}$ \\
\hline SCC generation mechanism & $\mathrm{M}$ \\
\hline Weld repair for irradiated materials & $M$ \\
\hline Surface improvement for SCC & $\mathrm{M}$ \\
\hline Repair for highly irradiated materials & M \\
\hline Integrity of repair weld of irradiated materials & $M$ \\
\hline Irradiation effect on repaired weld & $\mathrm{M}$ \\
\hline \multicolumn{2}{|l|}{ THERMAL AGING } \\
\hline Thermal embrittlement evaluation & $\mathrm{H}$ \\
\hline \multicolumn{2}{|l|}{ SG TUBE DAMAGE } \\
\hline SCC growth data of Ni based alloy & $\mathrm{H}$ \\
\hline Fracture evaluation of cracked thin tube & $\mathrm{H}$ \\
\hline \multicolumn{2}{|l|}{ CABLE INSULATION DEGRADATION } \\
\hline Application of NDT to cable in plants & $\mathrm{M}$ \\
\hline Evaluation by accelerated degradation data & $\mathrm{H}$ \\
\hline \multicolumn{2}{|l|}{ CONCRETE STRENGTH DECREASE } \\
\hline NDT for accurate strength prediction & $\mathrm{M}$ \\
\hline Strength decrease data by heating & $M$ \\
\hline Strength decrease data by irradiation & $\mathrm{M}$ \\
\hline \multicolumn{2}{|l|}{ CONCRETE SHIELDING ABILITY DECREASE } \\
\hline Monitoring of concrete shielding performance & $\mathrm{M}$ \\
\hline Concrete shielding ability data & $\mathrm{M}$ \\
\hline
\end{tabular}

\section{National Project Promoted by PLEC}

\subsection{Verification test}

The following themes are proposed in 2000 and 2001 as candidates of Verification Test.

(a) Research on NDT of SCC on Ni based alloy weld

This research was started in 2002 as verification test named NNW Project. Its outline is as follows. The detectability and sizing precision of UT and ECT for SCC
Table 2 Research specification of "SCC data in reactor coolant"

\begin{tabular}{|l|l|}
\hline theme & SCC data in reactor coolant \\
\hline $\begin{array}{l}\text { compo- } \\
\text { nents }\end{array}$ & primary piping(B), core internals(B) \\
\hline $\begin{array}{l}\text { pur- } \\
\text { pose }\end{array}$ & $\begin{array}{l}\text { obtain generation and growth data of IGSCC in } \\
\text { components made of ASS, especially low-C ASS } \\
\text { which has been developed and used as anti-SCC } \\
\text { material }\end{array}$ \\
\hline outline & $\begin{array}{l}\text { solve following parameter effects on IGSCC: } \\
\text { 1. materials : SUS304, SUS316 } \\
\text { 2. stress: SUS304L, SUS316L } \\
\text { distribution including residual stress }\end{array}$ \\
$\begin{array}{l}\text { 3. environments: } \\
\text { temperature, water, radiation }\end{array}$ \\
\hline period & in 5 years \\
\hline $\begin{array}{l}\text { target } \\
\text { output }\end{array}$ & $\begin{array}{l}\text { establish techniques to predict generation and growth } \\
\text { rate of IGSCC }\end{array}$ \\
\hline
\end{tabular}

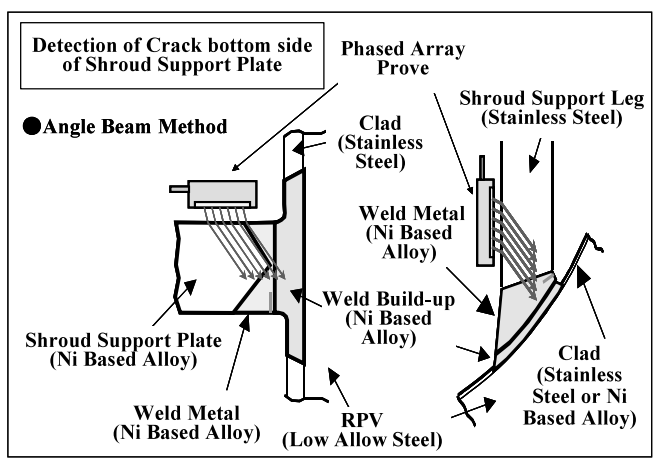

Fig. 4 SCC detection by phased array UT probe in Ni-based alloy shroud support

on Ni based alloy weld are going to be studied. Phased array UT probes are scheduled to be introduced. In order to optimize defect detectability and sizing precision, numerical simulation for ultrasonic wave propagation of UT and distribution of electro magnetic field generated by ECT are planned to be quoted. The conceptual arrangement of UT for shroud support plate is given in Fig. 4.

(b) Research on fatigue crack growth rate in PWR reactor coolant water environment

As well as fatigue life, fatigue crack growth rate is influenced by the environmental effect. Fatigue crack growth of carbon steel and austenitic stainless steel in BWR coolant condition was studied in a national project. This newly proposed research intends to establish a database of fatigue crack growth rate of austenitic stainless steel and nickel-based alloy in PWR primary coolant condition.

(c) Research on SCC growth rate under constant displacement condition

SCC growth rate is generally recognized to change whether the test is conducted under constant load condition or constant displacement condition. The former corresponds to $\mathrm{K}$-increase condition and the latter to $\mathrm{K}$ decrease condition where $\mathrm{K}$ means stress intensity factor composed of crack depth and stress. It is easy to do SCC 
test under constant load condition, but many real components in a nuclear power plant are situated under $\mathrm{K}$ decrease condition. In order to evaluate crack growth rate of austenitic stainless steel or nickel based alloy on more real condition this research has been proposed.

\subsection{SAT study}

In 2001, several research themes were performed as SAT study. Results of two researches are described bellow briefly.

( a ) Nondestructive evaluation of neutron irradiation embrittlement of monitoring specimen

There seems to be two ways of solution to avoid the deficiency of monitoring specimens after 40 years of designed operation. One is to reconstitute specimen using broken ones, another is to introduce nondestructive method to measure the embrittlement. Positron annihilation (PA) method and ultrasonic attenuation measurement are assumed to be such candidates. Basic studies related to these methods were performed by Prof. Matsui, Tohoku University in Japan. Following results are obtained:

Coincidence Doppler broadening (CDB) technique decreases background noise as shown in Fig. 5 (a). PA count ratio of $\mathrm{Fe}-0.1 \mathrm{w} \% \mathrm{Cu}$ alloy to that of pure $\mathrm{Fe}$ in Fig. 5 (b) shows that PA behavior of the alloy approaches from that of pure $\mathrm{Fe}$ to that of pure $\mathrm{Cu}$ as thermal aging time increases, which suggests $\mathrm{Cu}$ atoms coalesce to form precipitation with aging time.

Techniques to photograph continuously the movement of dislocation line in a test specimen located in the vacuum chamber of an electron microscope and loaded with tension load, was established. The techniques can be regarded as useful to understand dislocation interaction with point defects such as vacancy under vibration field caused by ultrasonic wave propagation.

(b) Dpa calculation by PC

Displacement per atom (dpa), which includes energy dependence of cross section and neutron energy spectrum of a reactor, can stand for the neutron irradiation damage of reactor materials more precisely than accumulated fluence. To calculate dpa, these quantities as function of energy and precise calculation technique to cover resonance integral are needed.

Through this research performed by Prof. Sekimura, Tokyo University in Japan, dpa calculations code based on ASTM-E693, which can be executed on personal computer, has been developed.

Developed code can be downloaded from the following Web site:

$$
\text { http://marie.q.t.u-tokyo.ac.jp/nprim/ }
$$

In 2002 FY (from April 2002 to March 2003), the following researches have been carried out:

(a ) Mechanism study of environmental effect on environment assisted crack growth

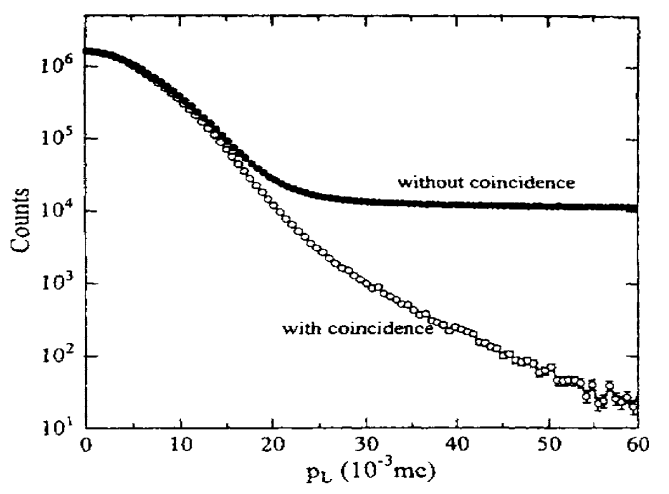

(a) Doppler Broadening (DB) of Fe with and without coincidence

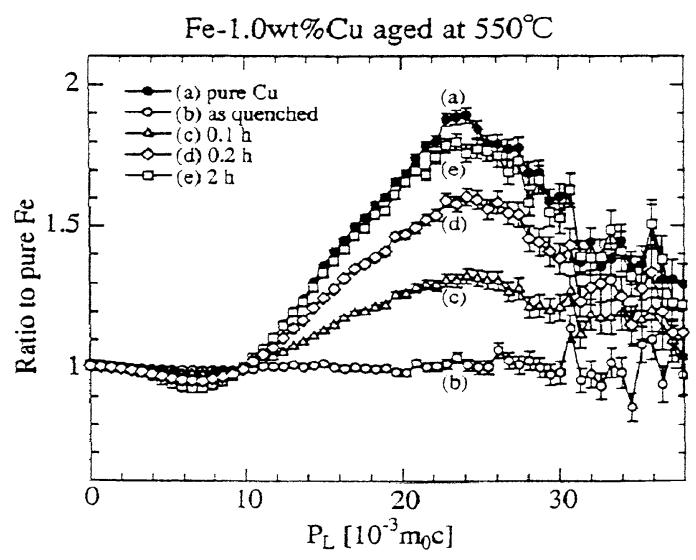

(b) $\mathrm{CDB}$ (ratio to $\mathrm{Fe}$ ) change of $\mathrm{Fe}-1.0 \mathrm{wt} \% \mathrm{Cu}$ due to thermal aging time at $550^{\circ} \mathrm{C}$

Fig. 5 Positron annihilation technology

( b ) Evaluation of accelerated irradiation effect based on micro mechanism consideration

(c ) Effect of neutron flux on irradiation damage of austenitic stainless steel utilizing removed parts from a real plant

\section{Another National Project Related to Aging in Japan}

Adding to the researches described in section 3, following research activities have been performed by each project in JAPEIC.

( 1 ) Fatigue life data of carbon steel, low alloy steel and austenitic stainless steel under reactor coolant condition $^{(2)-(4)}$

(2) Countermeasure for irradiation embrittlement of RPV steel

- Upper shelf energy evaluation method ${ }^{(5),(6)}$

- Reconstitution technology of surveillance speci$\operatorname{men}^{(7),(8)}$

( 3 ) Surface treatment to prevent SCC by laser technology

( 4 ) Repair welding technology for irradiated materials

( 5 ) SCC growth data in Ni based alloy weld 

SCC

(6) Initiation and growth data of irradiation assisted

( 7 ) Integrity assessment of flawed components with structural discontinuity. ${ }^{(9),(10)}$

( 8 ) Assessment of cable aging

Obtained results have been referred world widely.

\section{Conclusions}

The number of nuclear power plants operating more than 30 years has increased in Japan. Various aging related activities have been performed in Japan. To assure and improve the safety and reliability of aged nuclear power plants, it is important to continue and conduct research activities for evaluation methods of aging, inspection and monitoring method for aged components, preventive maintenance and refurbishment, in an effective manner and to apply the results of these research to aging management strategy.

\section{References}

( 1 ) Noda, T., et al., Current Approaches to Nuclear Power Plant Life Management in Japan, IAEA-CN-92/61, IAEA International Symposium on Aging Management of Nuclear Power Plants, Budapest, Hungary, (2002).

( 2 ) Iida, K., et al., Comparison of Japanese MITI Guideline and Other Methods for Evaluation of Environmen- tal Fatigue Life Reduction, Proc. of the ASME Pressure Vessel and Piping (PVP), (2001).

( 3 ) Higuchi, M., et al., Effects of Strain Rate Fluctuation and Strain Holding of Fatigue Life Reduction for LWR Structural Steels in Simulated LWR Water, Proc. of the ASME Pressure Vessel and Piping (PVP), (2001).

(4) Hirano, A., et al., Effects of Water Flow Rate on Fatigue Life of Carbon Steel in Simulated LWR Environment under Low Strain Rate conditions, Proc. of the ASME Pressure Vessel and Piping (PVP), (2001).

( 5 ) Sakamoto, K., et al., Development of Evaluation Method on Integrity of RPV at the Upper Shelf Region, ASME PVP-2002.

( 6 ) Otsuka, E., et al., Development of Aged Nuclear Power Plants Management Technology in Japan Power Engineering and Inspection Corporation, PLIM+PLEX' 99.

(7) Sakamoto, K., et al., Development of the Plant Life Management Technology for RPV Steels [-Current Status of Surveillance Test Specimen Reconstitution Program - ], ICONE-9.

( 8 ) Atago, Y., et al., Development of Reconstitution Technology for Surveillance Specimens, ICONE-10.

(9) Hosaka, K., et al., Structural Assessment of Flawed Equipment for Nuclear Power Plants Maintenance Criteria, Japan-Germany Seminar, (2001).

(10) Hosaka, K., Structural Assessment of Flawed Equipment Project (SAF), Houkoku To Kouen No Kai (original in Japanese, Proceeding of the 14th JAPEIC Seminar), (2001). 